\title{
ESTUDIOS DE URBANISMO Y ARQUITECTURA DE LOS SIGLOS XIX Y XX DESDE LA ÓPTICA DE LA HISTORIA DEL ARTE. CUESTIONES METODOLÓGICAS Y APROXIMACIÓN A LAS FUENTES
}

\author{
City Planning and Architecture Studies in the XIX and XX Centuries, from the Op- \\ tics of Art History. \\ Methdological Issues and Approach tho the Sources
}

Álvaro ÁvILA DE LA TORRE

Fecha de recepción: 20-01-2010

Fecha de aceptación: 29-01-2010

RESUMEN: Ante la realización de una tesis doctoral sobre la arquitectura y el urbanismo de los siglos XIX y XX desde la perspectiva de la Historia del Arte, las particulares características de estos campos en ese período cronológico concreto determinan la aparición de una serie de puntos objeto de debate. El primero es la diversa naturaleza de las citadas disciplinas, el segundo la libertad que caracterizó la arquitectura de la época y el tercero, que es también una de sus virtudes, la amplitud y heterogeneidad de las fuentes. De este modo, como primer objetivo, a través de mi ejemplo personal, ofrezco a los jóvenes investigadores unas sucintas pinceladas orientativas ante la multiplicidad y diversidad de la documentación existente y, en segundo lugar, pretendo dejar constancia de los problemas de metodología que surgieron, así como sus soluciones, sin querer aportar conclusiones generales o definitivas, sino con el objeto de enriquecer el debate.

Palabras Clave: Arquitectura, urbanismo, siglos XIX y XX, metodología, fuentes

ABSTRACT: Before completing a doctoral dissertation on $19^{\text {th }}$ and $20^{\text {th }}$ century architecture and city planning from the standpoint of Art History, the specific characteristics of these fields concretely in these chronological periods determine the appearance of a series of points in the debate. The first is the diverse nature of the aforementioned disciplines; 
the second the freedom that characterized the architecture of the period; and the third, which is also one of its virtues, the breadth and heterogeneity of the sources. In this way, as a first objective of my personal experience, I bring to the young researchers some succinct brush strokes in a way of guiding them through the current gauntlet of documentation and, in the second place, I endeavour to shed light on the problems in methodology that come up, just as solutions, without wanting to impose general or specific conclusions, intending rather to enhance the debate.

Keywords: Architecture, City planning, 19th and 20th century, Methodology, Sources

La arquitectura y el urbanismo de los siglos XIX y XX son dos campos de estudio, amplios y apasionantes, pero no exentos de complicaciones. En las siguientes páginas y a través del ejemplo práctico de mi tesis doctoral, pretendo informar sobre las fuentes a las que hubo que acudir, compartir las decisiones de índole metodológica que tomé y exponer algunos de los problemas que surgieron durante su realización.

La tesis doctoral que defendí en diciembre de 2007, titulada Arquitectura

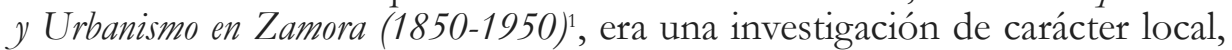
centrada en la ciudad de Zamora, aunque con vocación de enriquecer el conocimiento global, pues, a pesar de que resulte obvio, no podemos olvidar que la Arquitectura y el Urbanismo con mayúsculas sólo pueden conocerse desde la suma de los estudios particulares.

Con este objetivo, pretendí sacar a la luz la aportación que ofrece esa ciudad en estos dos ámbitos y en el período citado. Una localidad situada en la periferia española, en lo que podríamos considerar la España profunda, y habitada en 1850 por tan sólo 8.877 personas $^{2}$, que, sin embargo, demostró una calidad arquitectónica muy superior a núcleos de población de similares características, especialmente en los años comprendidos entre 1875 y 1930, arco cronológico que califiqué como la Segunda Edad de Oro de la arquitectura zamorana.

La bibliografía local posee un número relativamente elevado de estudios dedicados a la época de mayor esplendor constructivo del municipio, fechada entre el siglo XII y la primera mitad del XIII, en la que se elevaron más de veinte iglesias románicas, de las que muchas aún conservan gran parte de su estructura original ${ }^{3}$. Sobre las centurias posteriores, por lo que atañe a la arquitectura, han sido escasas las aportaciones, centradas en algunos edificios emblemáticos, pocos y de una calidad muy inferior a los erigidos en las centurias precedentes ${ }^{4}$. Aún más excepcionales han sido las aportaciones al urbanismo circunscritas al setecientos ${ }^{5}$. Esta falta de interés por parte de los investigadores está justificada por el hecho de que a lo largo de la Edad Moderna y los inicios de la Contemporánea, Zamora quedó sumida en un 
extenso letargo del que comenzó a despertar mediado el ochocientos. En ese momento, las destrucciones y los daños producidos por la Guerra de la Independencia y especialmente las desamortizaciones permitieron, desde el punto de vista económico, que el capital se oxigenara, desde el urbanístico, que algunas zonas del casco histórico se transformaran o quedaran a disposición de las autoridades y, desde el arquitectónico el nacimiento de una voluntad de renovar su caserío.

De este modo, se abría un período apasionante para los estudiosos de las dos últimas disciplinas pero, sorprendentemente y hasta el momento de la realización de mi tesis doctoral no contaban con ningún trabajo riguroso ${ }^{6}$.

En efecto, a partir del tercer cuarto del siglo XIX coincidieron una serie de circunstancias favorables: se ocuparon los edificios religiosos abandonados, Zamora perdió la condición de plaza de guerra - con lo que la muralla dejó de tener una utilidad defensiva- y, por último, se abrió la primera línea de ferrocarril. Factores que se convirtieron en importantes revulsivos para el comienzo de una notable transformación urbanística y arquitectónica de la localidad.

Ante estas circunstancias, precisamente en ese momento creí conveniente fijar el inicio cronológico de mi investigación. Desde entonces la ciudad no dejó de renovarse y tanto los poderes públicos como las clases acomodadas empezaron a promover construcciones que transformaron la imagen del municipio y embellecieron sus calles. Dentro del mismo proceso, se inició la expansión extramuros, con la urbanización de amplias zonas de residencia y la creación de parques, avenidas, etc.

Así las cosas y bajo esas premisas, durante el último cuarto del siglo XIX y las primeras tres décadas de la siguiente centuria, técnicos como Segundo Viloria (1853-1923, titulado en 1877), Gregorio Pérez Arribas (18771937, titulado en 1901), Francesc Ferriol (1871-1946, titulado en 1894) y Antonio García Sánchez-Blanco (1893-1963, titulado en 1918), entre otros, desarrollaron una intensa labor creativa que legó a la localidad un conjunto de obras sobresalientes por cantidad y alto nivel.

Por el contrario, en los años treinta de la pasada centuria hubo un descenso notable en la calidad de las construcciones, aunque ésta volvió a repuntar levemente en la Posguerra, momento en el que destacaron de manera especial las Escuelas Salesianas de San José (1947).

En función de estos hechos y esta evolución, decidí estudiar la arquitectura y el urbanismo en Zamora entre 1850 y 1950 y, de este modo, analizar el período más interesante de los últimos doscientos años. No obstante, hay que aclarar el criterio seguido para la fecha del colofón. De acuerdo con lo usual en los títulos de las tesis de mi disciplina, opté por que en el de la pre- 
sente también figuraran fechas "redondas". De cualquier manera, como creí conveniente abarcar toda la arquitectura del llamado Primer Franquismo, que estuvo marcada principalmente por corrientes historicistas, me vi obligado a incluir algunos inmuebles aislados proyectados a comienzos de los años cincuenta.

Una vez determinado el arco cronológico, inicié el proceso de recopilación de documentación. Dejando a un lado la extensísima bibliografía que fue necesario conocer, para la realización de esta investigación fue imprescindible la consulta de multitud de fondos documentales. A continuación haré referencia a ellos con el objetivo de orientar a posibles investigadores en un período caracterizado por la abundancia de fuentes de información.

La principal es la documentación de naturaleza municipal, que en $\mathrm{Za}$ mora se custodia en la actualidad en el Archivo Histórico Provincial. La sección más importante es la de Obras, donde están la práctica totalidad de las solicitudes de licencia de obras, tanto privadas como públicas. De sus correspondientes cajas extraje una ingente cantidad de información de muy variada naturaleza que fue necesario ordenar, clasificar y seleccionar. A ella sumé los datos de la de Mapas, Planos y Dibujos donde se guardan documentos gráficos relativos a diversos expedientes. Esta labor la completé con la información de otros fondos conservados en el mismo Archivo, como el de la Fiscalía de la Vivienda, los libros de actas municipales, la documentación emanada de la delegación de Hacienda, etc. Como decidí incluir referencias a los promotores, de gran utilidad fueron los libros de Registros Fiscales y, para las restauraciones monumentales, las actas y demás información correspondiente a la Comisión Provincial de Monumentos que, en parte, está en el archivo del Museo de Zamora.

La actividad constructiva llevada a cabo por otras instituciones públicas y, privadas me obligó a realizar pesquisas en diversos archivos de la ciudad. Éste es el caso del de la Diputación, para lo referente a las construcciones promovidas por ella y para ampliar los datos profesionales de los técnicos que ocuparon el cargo de arquitecto provincial. También el Diocesano, para lo relativo a obras religiosas, tanto parroquias, iglesias y conventos, para el cementerio, para el capítulo de las intervenciones en el patrimonio y para conocer la labor de los arquitectos diocesanos. Aquí, entre otros, revisé los fondos de la Secretaría de Cámara, los libros de fábricas, las actas de la Junta de Reparación de Templos y el Boletín Eclesiástico. Asimismo, visité el Archivo de la Jefatura Provincial de Obras Públicas, donde custodiaban la información referente a puentes y carreteras y el del Instituto Nacional de Estadística.

Naturalmente tuve que ampliar mis pesquisas fuera del municipio. De este modo, fueron de suma ayuda los fondos de diferentes ministerios, con- 
sultados en sus correspondientes sedes ubicadas en Madrid -Vivienda para el Plano General de Ordenación de las Posguerra, Fomento para los expedientes académicos de los ingenieros, Cultura para las intervenciones en el patrimonio, etc.-, en Ávila y Segovia -para las cuestiones militares- y sobre todo el Archivo General de la Administración Española de Alcalá de Henares -construcciones escolares, expedientes académicos de arquitectos, ferrocarril, etc.-. Sin embargo, hay que decir que en algunos casos, especialmente en edificios emblemáticos promovidos por el Gobierno Central, como la Audiencia Provincial o el Cuartel Viriato, mi búsqueda, pese a haber sido persistente y minuciosa, resultó, en gran medida, infructuosa.

Como elementos complementarios pero a través de los cuales he obtenido mucha información, consulté la prensa de la época, especialmente la local, también archivos fotográficos, boletines de diferentes instituciones, revistas generalistas y especializadas, etc., fuentes que fueron de gran utilidad, pues en ocasiones sirvieron tanto para conocer los proyectistas de algunos inmuebles y sus fechas de realización como para reconstruir la evolución en la concepción y materialización de otros muchos.

Por lo que respecta a los arquitectos y otros artífices, hay que lamentar la pérdida de sus archivos personales y el hecho de que ninguno de ellos dejara testimonios escritos ni publicara libros ni colaborara en prensa. Es por ello que para conocer su personalidad y su trayectoria profesional recurrí a la documentación conservada en los archivos citados-secciones de personal y expedientes académicos- y los de las Reales Academias de Bellas Artes de San Fernando de Madrid -para los arquitectos titulados antes de la creación de la Escuela de Arquitectura de Madrid- y de la Inmaculada Concepción de Valladolid -para datos relativos a los maestros de obras-, así como en los colegios oficiales de arquitectos de Zamora, Madrid y Barcelona, el correspondiente a la Hermandad de Arquitectos y a las Guías de arquitectos que se editaban periódicamente. Mi deseo de ampliar el conocimiento sobre los facultativos que trabajaron en la localidad, me llevó al Archivo Administrativo del Ayuntamiento de Barcelona y al de la Diputación de Cádiz para el caso de Francesc Ferriol, al Municipal de Alcalá de Henares para Martín Pastells Papell (1856-1926, titulado en 1885), al de Teruel para Gregorio Pérez Arribas, etc.

Todo ello hasta llegar a un total de casi cuarenta fondos documentales consultados.

Pasando a una exposición más pormenorizada de la investigación, en las primeras páginas y a modo de introducción, incluí una breve exposición de tipo histórico, donde explicaba los condicionantes socioeconómicos que vivió el municipio en la centuria que abarca el trabajo y, seguidamente, dediqué un primer gran capítulo al urbanismo. 
En este apartado opté por un criterio geográfico, con una metodología que me pareció más didáctica que la cronológica, pues precisamente el momento de gestación de los diferentes sectores y su situación en el conjunto de la ciudad determinaron su evolución posterior y la mayor o menor incidencia de las transformaciones que sufrieron en el período. Con este fin y en función de su origen, dividí la ciudad en cinco áreas.

La parte más antigua es el casco, situado en la zona más occidental. Fue el primer sector consolidado tras la Reconquista de la localidad en el año 893 y en el siglo XI alcanzó su máxima extensión, desde el Castillo hasta la actual Plaza Mayor. Completamente amurallado, en su extremo oriental se abría la denominada Puerta Nueva ${ }^{7}$. Aquí las modificaciones urbanísticas llevadas a cabo en las pasadas centurias fueron menores y la renovación del caserío más limitado.

El segundo sector es el burgo medieval, ampliación del cerco anterior, que quedó constituido y amparado por una cerca de piedra en el siglo XII. Entre 1850 y 1950 sufrió una alteración profunda y fue el verdadero espejo de las aspiraciones de la nueva clase burguesa dominante.

Consideré el tercer ámbito urbano la Pobladura del Valle, un barrio ubicado junto al río Duero, al pie de la meseta donde se asienta el resto del municipio, y que también contó con protección muraria desde tiempos medievales. Su posición secundaria hizo que la atención de los promotores públicos y privados durante el arco cronológico de mi trabajo fuera muy reducido.

Englobé en un cuarto grupo todos los arrabales históricos. Éstos son de muy diversa naturaleza, ubicación y relación con núcleo central, pero decidí unificarlos en un solo apartado por compartir su carácter periférico y, en líneas generales, por no haber sido objeto de dedicación hasta bien avanzado el siglo XX.

Por último, estudié el ensanche, la zona de expansión extramuros gestada una vez superado el ecuador de la centuria decimonónica. Dada su amplitud geográfica, tomé como referencia la actual avenida del Príncipe de Asturias y la subdividí en norte y sur. Fue por un criterio práctico aunque bien es verdad que el septentrional fue inicialmente más marginal y su colmatación respondió a su función de vínculo entre el burgo y la estación de ferrocarril. Respecto al meridional, la creación de la Glorieta o Paseo de Requejo forjó su carácter residencial y desde su gestación fue escogido por las clases más acomodadas para elevar viviendas unifamiliares.

La única excepción a la clasificación geográfica apenas expuesta fue cuando abordé el Plano General de Ordenación, pues, redactado por la Dirección General de Arquitectura en la Posguerra, 
planteaba intervenciones en la ciudad consolidada, los barrios periféricos y el primer y el segundo ensanche.

En líneas generales, tres claves definen la evolución de trazado urbano de Zamora en los cien años de este estudio: la modificación del entramado medieval, el establecimiento de mejoras urbanas y la imparable expansión hacia el este.

Por lo que respecta a la Zamora histórica, conformada por el casco y el burgo medieval, estudié las intervenciones más importantes, que fueron los planos de alineación de calles y plazas, la creación o acondicionamiento de zonas de esparcimiento para los ciudadanos y la apertura de nuevas vías. Son muy numerosas propuestas, pero la de mayor interés fue el ambicioso aunque fallido proyecto de 1908 para ampliar la Plaza Mayor, que incluía la desaparición del templo de San Juan de Puerta Nueva y las casas adosadas al mismo, y que corrió a cargo del arquitecto Francesc Ferriol.

Entre las mejoras urbanas, cabe citar la extensión de la red de alcantarillado y de suministro de agua, la pavimentación de las calles y la generalización de la iluminación eléctrica, servicios de los que dispusieron los zamoranos desde el último cuarto del siglo XIX. Asimismo el Ayuntamiento, de acuerdo con una táctica muy extendida en la época, adecuó espacios para el asueto de los ciudadanos, entre los que destacaron el Parque de San Martín y el Bosque de Valorio y elevó monumentos conmemorativos, entre los que sobresale el de Viriato, erigido en la plaza homónima.

Por último, sobre el diseño de nuevas vías, debemos citar la creación de la calle Viriato que, junto a la contigua plaza de Sagasta dio lugar, por lo que se refiere a nuestro ámbito cronológico, a uno de los conjuntos urbanos y arquitectónicos más interesantes de Castilla y León.

En referencia a la expansión del municipio, un apartado importante lo dediqué a tratar la destrucción de la muralla, que fue el primer síntoma de la transformación que estaba sufriendo la ciudad. Dada su trascendencia, analicé su derribo desde el punto de vista urbanístico, social, psicológico y en relación con el pensamiento higienicista de la época. La acción de la piqueta se concentró en los lienzos septentrional y oriental, pues limitaban con áreas con escaso desnivel respecto a la ciudad histórica y, por tanto, hacia donde fue creciendo Zamora, y no contaban, según estimaron en su momento las autoridades competentes, con ningún tipo de protección a causa de su escaso valor histórico ${ }^{8}$.

Contemporáneamente, observamos los primeros atisbos de crecimiento extramuros. Se trazaron los primeros barrios y empezaron a surgir hoteles promovidos por la burguesía, que fueron construidos en los alrededores del Paseo de la Glorieta, zona verde que, en la primera década del siglo 
XX, fue ampliada, cerrada al tráfico y dotada de un quiosco para la música. Asimismo, en 1893, Eugenio Durán (1824-1905) concibió un ambicioso proyecto, nunca materializado, para la creación de un gran parque en la actual avenida de las Tres Cruces.

A medida que fueron avanzando los decenios, la mayor ocupación de los terrenos ubicados al este de la ciudad alertó a las autoridades locales sobre la necesidad de llevar a cabo una planificación global del ensanche. Como consecuencia, el arquitecto Francisco Hernanz (1896-1971, titulado en 1923) diseñó en 1929 un anteproyecto para el plano general del mismo. Fue una propuesta ambiciosa y, aunque sufrió algunas modificaciones antes de su aprobación, determinó y rigió la configuración de ese espacio periférico hasta la aprobación, ya en la Posguerra, del Plano General de Ordenación.

Tras el análisis de la evolución urbanística de Zamora entre 1850 y 1950 me centré en la arquitectura. Para realizar un estudio amplio y ordenado, tal y como ocurre con otros trabajos de similares características, creí conveniente estructurarla en estilos siguiendo un criterio cronológico en función de la aparición de los primeros ejemplos. En un segundo nivel tuve que realizar la clasificación estilística de cada uno de los edificios. En este punto debo dejar constancia de su mayor dificultad, pues cuando no se manejan las obras emblemáticas de la arquitectura española y, por el contrario, nos movemos en un contexto local, suele ser habitual que muchas de las construcciones pequen de una concepción "ecléctica", en la que se entremezclan elementos de diferentes corrientes.

Todo ello responde parcialmente a la ambigüedad que caracterizó muchas de las manifestaciones artísticas y los estilos de finales del siglo XIX y principios del XX, impregnados por la libertad que defendía el Romanticismo y la derivada del propio planteamiento ecléctico, lo que produjo que, probablemente por primera vez en la Historia del Arte, tengamos dificultades para establecer de forma taxativa las características de cada uno de estos movimientos. No sólo sucedió en arquitectura, ocurrió lo mismo entre la pintura simbolista y la modernista o al abordar el monumento conmemorativo, en el que es difícil deslindar la fase realista de la romántica.

Como consecuencia y premisa inicial a la hora de abordar los diferentes inmuebles, siempre opté por el estilo dominante, aunque a la hora de hacer el análisis dejé constancia del resto de improntas.

Parece conveniente poner un ejemplo concreto, el mayor o menor peso de los elementos modernistas en edificios eclécticos, por ser una disyuntiva habitual cuando se estudia la arquitectura de esta época, y la consiguiente dificultad a la hora de establecer su filiación estilística. Como punto de partida cabría recordar la controvertida indefinición del Eclecticismo, que ya fue planteada por Pedro Navascués en el artículo "El problema del Eclecticismo 
en la arquitectura española del siglo XIX"9 y también su relación con el Modernismo, pues el mismo profesor lo consideró una aceleración precipitada del eclecticismo en su fase final, que, con la excepción de la variante catalana, estuvo centrada principalmente en los aspectos decorativos ${ }^{10}$.

Dicho esto, en estudios similares dedicados a otras localidades del interior peninsular, la mera existencia de leves pinceladas modernistas en los inmuebles justificó que fueran incluidos en esa corriente. Sin embargo, el caso de Zamora es muy diferente y, dadas las características de su arquitectura fue factible ser restrictivo. La razón es que en esta ciudad, como desarrollaremos más adelante, al haber un corpus modernista muy amplio, realizado por Francesc Ferriol, un arquitecto formado en Cataluña, con clara evocaciones de Antoni Gaudí (1852-1926, titulado en 1878) y Lluís Domènech i Montaner (1850-1923, titulado en 1873), era preciso ser más exigente a la hora de determinar qué construcciones debían estar en el apartado dedicado al Modernismo.

Otra cuestión de envergadura surgió al tratar la incidencia de los nuevos materiales. Su empleo estuvo unido al desarrollo de tipologías antes desconocidas, pero en el caso del ladrillo no podemos pasar por alto la existencia de ciertos revivals historicistas que lo reivindicaron como seña de identidad. Que la presencia de piezas aplantilladas fuera una característica sustancial de las estéticas de raíz hispanomusulmana y al mismo tiempo fuera habitual encontrarlo en la tipología industrial, ha dado lugar a un debate entre los investigadores contemporáneos a la hora de realizar una clasificación respecto a la primacía del estilo o del elemento constructivo. Tanto Josep $\mathrm{M}^{\mathrm{a}}$ Adell como Javier Hernando se decantaron por la mayor importancia de las cuestiones físicas, por lo que hablaron de arquitectura de ladrillo ${ }^{11}$. Como consecuencia, el primero incluyó en su estudio sobre las construcciones de ese material en Madrid edificios neomudéjares junto a otros que no pertenecen a esa corriente ${ }^{12}$.

Zamora no es diferente. En mi tesis en todo momento decidí distinguir entre los inmuebles en los que los técnicos emplearon la fábrica latericia sin ningún fin estilístico y aquéllos en los que introdujeron connotaciones artísticas, pero Ascensión Rodríguez, en la parte más técnica de su reciente trabajo de Grado, optó por ordenar los edificios cronológicamente sin acudir a criterios estéticos ${ }^{13}$.

Tras estas aclaraciones iniciales, en el primero de los capítulos, dedicado a lo que denominé epígono neoclásico, recogí los inmuebles proyectados en la ciudad en el tercer cuarto del siglo XIX, pero también incluí un análisis de los instrumentos legales arbitrados en este campo por las autoridades zamoranas. Entre ellos destacan la Ordenanzas Municipales de 1890, que rigieron la arquitectura de la ciudad hasta la Posguerra. 
Siguiendo la clasificación antes señalada, la construcción en 1864 de la primera estación de ferrocarril me ayudó a determinar el inicio del capítulo dedicado a la influencia del proceso industrial en la arquitectura. En él me hice eco de la incidencia que tuvo en Zamora el empleo de los nuevos materiales, principalmente el ladrillo de fabricación industrial y el hierro. De este modo y en armonía con uno de los principios de la arquitectura de la época de que a cada tipología le correspondía un estilo, en este apartado hablé de las fábricas, principalmente harineras -dada la importancia de la producción de trigo en la provincia-, el Mercado de Abastos (1902), el Matadero Municipal (1929), quioscos de música, etc. Asimismo, también traté el uso del hierro en la arquitectura doméstica, pública y religiosa, aunque en elementos no estructurales, como miradores, antepechos, rejas y verjas, cuyo repertorio es amplio y variado y cuyo artífice más sobresaliente fue el arquitecto Segundo Viloria. Por último, dediqué unas páginas a la denominada arquitectura de ladrillo, en el que están los edificios no industriales, básicamente viviendas, donde se empleó la fábrica latericia como material de construcción y en los que no hay connotaciones estilísticas.

Un capítulo importante debido a su gran desarrollo es el del Eclecticismo, cuya existencia se prolongó a lo largo de lo que califiqué como Segunda Edad de Oro de la Arquitectura Zamorana. Este estilo, en armonía con la clasificación decimonónica, fue elegido para los edificios públicos, pues servía perfectamente a los deseos de la época, momento en el que se buscaba un lenguaje que demostrase empaque y representatividad. Buen ejemplo de ello fue el Palacio Provincial (1867) que, aunque ideado inicialmente por Pablo Cuesta (nacido en 1833 y titulado en 1856), su aspecto definitivo fue configurado por Segundo Viloria, y donde intervinieron el pintor Ramón Padró y el escultor Eduardo Barrón.

Como consecuencia del peso que tuvo esta corriente en el campo de la edilicia, creí conveniente englobar todas las construcciones promovidas por las administraciones en un mismo apartado, en el que también hablé, entre otras, del Teatro Principal (1876), proyectado por Eugenio Durán, o el Casino (1905), diseñado por el arquitecto Miguel Mathet (1849-1909, titulado en 1872), quien seguramente contó con la colaboración de su hijo Jerónimo Pedro (titulado en 1902).

Me detengo un instante en este inmueble porque su clasificación puede resultar controvertida y me permite enlazar con un tema expuesto anteriormente. En un primer golpe de vista destaca el arco rebajado que acoge cinco vanos y un tratamiento muy planista que evoca la Sezession, pero si lo miramos con detenimiento, no hay, siendo el Modernismo fuera de Cataluña un estilo básicamente centrado en la decoración, casi ningún detalle ornamental que recuerde ni a la variante citada ni al Art Nouveau. Por ejemplo, los azulejos con candelieri de Zuloaga fueron un diseño típico de su etapa regionalista ${ }^{14}$. 
Además, hay acroterios, elemento por antonomasia de ascendencia clásica. Las cabezas distan mucho de las que Ferriol incorporó a su repertorio y se alejan del aspecto melancólico y lánguido del Modernismo, de hecho, podríamos decir que son muy severas.

Es verdad que la combinación de materiales y la integración de las artes fueron consustanciales a la arquitectura modernista, pero no es menos cierto que esto también fue característico del Eclecticismo, como ejemplifica el Ministerio de Fomento de Madrid, obra de Ricardo Velázquez Bosco (18931897, titulado en 1881). Por último, las fachadas laterales son abrumadoramente eclécticas sin ningún detalle modernista.

Sin duda, si este inmueble estuviera en otra capital castellano-leonesa, el Casino se encontraría dentro del capítulo del Modernismo. Sin embargo, en Zamora, al haber un corpus modernista de mucho peso y uniforme en lo que se refiere especialmente a la producción de Ferriol, no me pareció coherente equipararlo con esas obras.

Por las mismas circunstancias expresadas al aludir a los edificios públicos, esto es, la frecuente elección del Eclecticismo para ciertas tipologías, dediqué un apartado a las numerosas construcciones educativas que estilísticamente quedan englobadas en esa corriente, que en general se presentó en su versión más clasicista, indicada por aquel entonces para la arquitectura escolar.

El Eclecticismo también tuvo un importante desarrollo en la arquitectura privada, pues, por su gran efectismo, la clase acomodada lo eligió para sus viviendas, con la clara intención de buscar en ellos la representatividad de su status personal. En ocasiones, algunos de estos edificios se convirtieron en hitos de los espacios urbanos, caso de la casa de Bernardino Pinilla (1927), proyectada por el arquitecto Antonio García Sánchez-Blanco en 1927, o la Casa Andreu (1928), de Gregorio Pérez Arribas. Ambas están situadas en la glorieta que sustituyó la Puerta de Santa Clara, como muestra de la ruptura del cerco amurallado y la transformación de los viejos arcos de entrada en escaparates de la ciudad burguesa, más aún en este caso, en el que las fachadas de los inmuebles se orientaron hacia la zona arbolada más importante del ensanche.

La casa de Valentín Guerra, diseñada por Gregorio Pérez Arribas en 1907, es otro ejemplo de la ambigüedad de algunos edificios de la época. En él se ven varios elementos modernistas, como las lánguidas figuras de la portada y la sinuosa cornisa, e incluso hay algunos detalles inspirados en la Casa Lleó Morera (1902) de Domènech i Montaner, como los arcos ultrasemicirculares del último piso. Esta construcción ejerció una gran influencia fuera de Cataluña a raíz de haber obtenido el premio del concurso de fachadas del Ayuntamiento de Barcelona en 1905 y aparecer publicada con mucha fre- 
cuencia en las revistas contemporáneas. Por citar algún caso, se perciben sus ecos en la denominada Casa de Príncipe (1906) de Valladolid de Jerónimo Arroyo (1871-1946, titulado en 1899) ${ }^{15}$ o en la Casa de Torico (1912) de Pau Monguió (1865-1956, titulado en 1889) en Teruel ${ }^{16}$. Pero frente a eso, en la zamorana predominan los elementos eclécticos, en el tratamiento de la entrada, los antepechos de fábrica, las guirnaldas con mascarones que coronan los miradores, etc. Esta lejanía de las formas ortodoxas del Modernismo queda reafirmada si observamos el plano original, en el que Arribas proponía la elevación de sendos torreones poligonales y almenados en las esquinas, así como merlones como coronamiento de los ejes de vanos, que aportaban pinceladas historicistas.

La libertad consustancial al Eclecticismo permitió la simultaneidad de varias modalidades. La de mayor importancia fue la variante polícroma, muy efectista, que en la ciudad cuenta con interesantes ejemplos, como el Instituto Claudio Moyano (1901), cuyo diseño original fue realizado por Miguel Mathet, o el Cuartel Viriato, obra del ingeniero militar Francisco Vidal (nacido en 1877 y titulado en 1898) y cuyas obras comenzaron en 1919 y, por lo que respecta a la arquitectura privada, sobresale la casa del industrial harinero Gabino Bobo, proyectada por Segundo Viloria en 1916.

Por el contrario, el Pintoresquismo tuvo poco eco en la localidad. Buena prueba de ello es que tan sólo se elevaron cinco inmuebles, en su mayor parte, como correspondía a esta corriente, viviendas para los guardas de los parques. De cualquier manera, algunos de ellos son dignos de mención por dos razones. La primera, su temprana fecha de construcción, como la casa del guarda del Bosque de Valorio, anónima, que ya existía en 1881. La segunda, su singularidad a nivel regional, pues es un estilo muy infrecuente en Castilla y León.

En el capítulo correspondiente se aborda la incidencia del Neomedievalismo. Naturalmente, su presencia fue muy recurrente en la arquitectura religiosa. Ésta quedó englobada en un apartado específico, que precedí de una introducción histórica sobre las vicisitudes de las congregaciones religiosas en la Zamora de la época. Los mejores ejemplos fueron la iglesia de Nuestra Señora de Lourdes, proyectada en 1905 por el arquitecto Joaquín de Vargas (1855-1935, titulado en 1883), y el templo parroquial de San Lázaro, que por su tardía fecha, 1929, corrobora la pervivencia del estilo en esta tipología.

Bastante más llamativa fue la elección del Neomedievalismo para la arquitectura civil, puesto que, aparte de algunos edificios neomudéjares, con obras muy representativas de Segundo Viloria, sobresale la casa de los Marqueses de Arjona. Fechada hacia 1890, en ella priman los elementos neorrománicos. Si curioso resulta la elección de esta estética para una construcción 
privada, más sorprendente es que el proyectista, a día de hoy anónimo, copiara fielmente los capiteles del sepulcro medieval de la iglesia de Santa María Magdalena.

El capítulo titulado La arquitectura funeraria como "museo de arquitectura": El Cementerio de San Atilano y sus panteones, está dedicado al camposanto zamorano. Respecto al mismo, debo hacer varias aclaraciones. La primera es que ante la inexistencia de un trabajo sobre el tema y aunque se escapaba de mi cronología, estudié no sólo las sepulturas, sino también la evolución de la necrópolis y abarqué toda su historia, desde su gestación y creación en 1833 hasta las diferentes ampliaciones, los reglamentos, etc. Por lo que respecta a la arquitectura funeraria, dado que para la mayor parte de los ejemplos y, de nuevo, teniendo en cuenta los planteamientos de la época, los arquitectos se decantaron por estéticas neomedievales, podrían haberse englobado en el capítulo anterior; pero sus características tipológicas fueron determinantes a la hora de crear un apartado específico para ellos. Las construcciones de la necrópolis de Zamora nunca alcanzaron la categoría de otras áreas geográficas o de otras ciudades, incluso de Castilla y León, aunque, sin embargo, hay algunas significativas, como el panteón de la familia Bobo, obra tardía proyectada por Pérez Arribas en 1928.

Especial importancia tiene la arquitectura modernista en la ciudad que, en gran medida, respondió a la presencia en la localidad del arquitecto barcelonés Francesc Ferriol, quien comenzó su carrera profesional colaborando con Domènech i Montaner. Llegó a Zamora en 1908, a los pocos meses de ser nombrado arquitecto municipal, y permaneció en ella hasta 1916. En todos sus proyectos, incluido uno para el Matadero Municipal (1909), demostró una gran meticulosidad y un perfecto dominio del lenguaje imperante en Cataluña por aquel entonces. Su labor, importante de por sí, patente en los edificios conservados y en los derribados que he conseguido documentar en todos los casos, es mayor si tenemos en cuenta la influencia indirecta en sus colegas, quienes, especialmente Pérez Arribas, bien incorporaron elementos modernistas a su repertorio, bien se vieron obligados a buscar soluciones compositivas y ornamentales más arriesgadas que pudieran competir con los diseños de Ferriol. Éste fue autor de multitud de inmuebles modernistas de gran calidad, que prácticamente habían sido ignorados por la historiografía hasta que realicé mi trabajo. En este punto, me permito expresar mi orgullo como historiador del arte, ya que a raíz de mi investigación el Ayuntamiento de Zamora solicitó y consiguió en marzo del 2009 el ingreso de la ciudad en la Ruta Europea del Modernismo. Así las cosas, todo ello es muy significativo y revelador a la hora de comprobar el desconocimiento que había de la arquitectura zamorana hasta la realización de esta tesis y confirma el alto nivel que alcanzó. 
A diferencia del Modernismo, el Regionalismo tuvo una incidencia mucho menor y resultó francamente tardío. Respecto a sus valores formales, dado que la libertad consustancial de la arquitectura de entonces es uno de sus atractivos pero también da lugar a muchas indefiniciones, conviene añadir una aclaración, pues, en referencia a esta corriente arquitectónica la presencia de rasgos del Historicismo en las variantes cultas del Regionalismo ha sido fuente de controversia y dificulta desligar ambos estilos.

En el pabellón de la Exposición Universal de París de 1867, obra de Jerónimo de la Gándara (nacido en 1825 y titulado en 1848), fue la primera vez en la que se tomó Monterrey como modelo representativo de un ámbito geográfico, en ese caso de España ${ }^{17}$. Por cronología, esa elección estaba en consonancia con el desarrollo que el Neorrenacimiento había tenido en España durante el reinado de Isabel II. Al final del siglo, en la Exposición de París de 1900, José Urioste (1850-1909, titulado en 1879) volvió a escoger el mismo modelo para mostrar la imagen arquitectónica del país; con sus propias palabras con el deseo de recordar la poderosa España de Carlos $V^{18}$. En ese momento se sumaban otras circunstancias, pues coincidió con la pérdida de las colonias y la introspección derivada del 98. Por el contrario, cuando en la segunda década del siglo XX, impulsado por Leonardo Rucabado (1875-1918, titulado en 1900) y Aníbal González (1876-1929, titulado en 1902) ${ }^{19}$, arraigó el Regionalismo, el primero consideró que toda la obra de Rodrigo Gil de Hontañón era una apoyatura fundamental para la arquitectura específicamente montañesa, y dentro de los convencionalismos de la época, afirmó que la arquitectura cántabra que le servía de inspiración no era sólo la realizada en esa región, sino también la ideada en otras partes por canteros nacidos allí. En este punto, hay que matizar que hasta hace poco tiempo, en concreto hasta que John D. Hoag y Antonio Casaseca demostraron que era natural Rascafría (Segovia) ${ }^{20}$, aún se consideraba que Gil de Hontañón había nacido en la citada comunidad del norte peninsular.

En la misma línea, en Salamanca, como puso de manifiesto la tesis de José Ignacio Díez Elcuaz, la huella de Monterrey estuvo presente en edificios de los años veinte y treinta del siglo pasado, como el Cuartel de Caballería (1920) o las sedes de la Compañía Telefónica (1928) o del Instituto de Previsión (1928), y los propios arquitectos indicaron su deseo de realizar una arquitectura de corte local y no nacional ${ }^{21}$.

Respecto a Zamora, en general las memorias no informan al respecto, y aunque estuvieron presentes las diferentes variantes del Regionalismo, gracias a la documentación se puede tomar como propia la salmantina. La estación es el inmueble más ilustrativo porque el ingeniero Antonio Salazar (nacido en 1897 y titulado en 1921) justificó el empleo del citado palacio renacentista como opción autóctona por estar basado en el estilo genuinamente castellano del Renacimiento. Además, la Comisión de Ferrocarriles del Ministerio 
de Obras Públicas propuso modificar el proyecto, sugirió evocar el Hospital del Rey de Burgos y puso énfasis en que también era una solución local. Esto es una arbitrariedad, pues no es de Zamora, pero demuestra la voluntad de hacer algo regionalista, en contraposición con la insistencia, emanada de los textos del XIX, en establecer una arquitectura de carácter nacional partiendo de esos mismos modelos.

En este apartado de mi investigación, aludo a la Casa Ramos, lamentablemente derribada, un edificio mítico en la memoria colectiva de los zamoranos, del que no se conserva el expediente entre la documentación municipal, pero que quizás fuera diseñado por Santiago Madrigal (1878-1923, titulado en 1904). Otros dignos ejemplos del Regionalismo montañés, todos ellos diseñados por Sánchez-Blanco, fueron la casa de Osorio Pinilla, de 1928, o la espléndida Casa de la Peña, de 1931, sin duda, uno de los mejores proyectos de este arquitecto madrileño.

Los años treinta del siglo pasado marcaron una crisis en la arquitectura de la ciudad. La brillantez, la originalidad y la variedad que se habían alcanzado en las décadas anteriores no pudieron sobrevivir a la crisis económica que vivió la localidad por aquel entonces. Por ello, a partir de esa década, la indefinición estilística caracterizó muchos edificios y esto me llevó a optar por seguir un criterio cronológico y abandonar la clasificación por corrientes arquitectónicas que había establecido para los capítulos anteriores.

En el dedicado a la arquitectura de la Segunda República recogí obras del zamorano Enrique Crespo (1898-1963, titulado en 1924), quien realizó interesantes propuestas racionalistas, con profundas innovaciones, sobre todo en la concepción de las plantas y en la distribución interior. Asimismo, la incidencia del Movimiento Moderno en la arquitectura escolar hizo necesario incluir unas páginas con las propuestas que para esa tipología se hicieron en Zamora, entre las que sobresale la Escuela Normal de Maestros (1933), diseñada por Joaquín Muro Antón (1892-1980, titulado en 1916). En el mismo arco cronológico también tuvo importancia el Art déco, estilo en el que destacó Sánchez-Blanco, quien creó originales soluciones, como la fachada del hotel Franco-Español, inmueble ideado en 1933. Por último y en alusión a lo expresado en el párrafo previo, determiné tratar de manera separada algunas propuestas arquitectónicas del momento carentes de connotaciones estilísticas relevantes, como la sede de Correos (1932) o la Prisión Provincial (1935).

Para el último período que abarca mi investigación, la Posguerra, como en el caso anterior, opté por seguir un criterio temporal. Los motivos coinciden con lo acontecido con la Segunda República: por un lado, la variedad de soluciones estéticas y, por otro, la existencia de un elevado número de edificios sin filiación artística clara. A estos condicionantes se une la exigua bi- 
bliografía existente sobre la arquitectura del Primer Franquismo, lo que hacía difícil establecer puntos de partida basados en estudios que abarcaran ese arco cronológico en otras localidades españolas. Así, decidí crear apartados en función de los diferentes estilos imperantes en el momento, aunque a decir verdad el carácter anodino de un gran número de construcciones me llevó a clasificar muchas de ellas bajo un epígrafe titulado la arquitectura desornamentada. A pesar de lo dicho en Zamora se construyó el inmueble más relevante de ese período en Castilla y León, las Escuelas Salesianas de San José, proyectadas por Luis Moya (1904-1990, titulado en 1927) en 1947 y convertidas en Universidad Laboral en 1960. Del mismo modo, hubo aportaciones historicistas y regionalistas, renacieron los monumentos conmemorativos, se realizaron propuestas megalómanas de corte fascista y pervivió el Art déco de sesgo expresionista y el Racionalismo -destacando el grupo de viviendas obreras en los Cascajos de 1944, obra de Jesús Carrasco-Muñoz (1899-1960, titulado en 1928)-. Todo ello, también convierte la arquitectura zamorana del período en un caso representativo, por esta multiplicidad de tendencias, de la desorientación que imperaba por entonces en el panorama español.

Además del estudio cronológico de las diferentes corrientes de la arquitectura, consideré preciso incluir un capítulo dedicado a la decoración interior. No obstante, debo matizar que para los edificios públicos opté por realizar su estudio conjuntamente al estilístico, pues, generalmente, en estos inmuebles, la ornamentación respondía a un programa iconográfico ideado de manera simultánea y en estrecho maridaje con la propia concepción de los alzados. Es por ello que, en el apartado al que me refiero en este momento, me centré, por un lado, en las viviendas que han llegado hasta nosotros con piezas y detalles notables -entre ellos algunos modernistas- que clasifiqué en apartados: las puertas de ingreso, los portales, las escaleras, la decoración de las habitaciones, etc. Por otro, presté atención a los comercios, dando a conocer los proyectos de varios establecimientos de los siglos XIX y XX que, en ocasiones, en la actualidad aún conservan su diseño original.

En este sentido hay que recordar que, aunque lamentablemente hoy el número de ejemplos es muy inferior al que debió existir en su momento, permiten suponer la alta calidad que Zamora también demostró en este aspecto. Un patrimonio arquitectónico y ornamental que hasta el momento era, en su mayoría, desconocido.

Junto con el estudio estilístico y decorativo de la arquitectura de la ciudad en los cien años de esta investigación, decidí incluir un capítulo sobre tipologías, sobre el que debo realizar dos aclaraciones.

En primer lugar, la representación y diversidad tipológica de la arquitectura zamorana del período imposibilitaba establecer una secuencia y no permitían realizar un análisis de esta naturaleza para algunas categorías, como 
hospitales o cuarteles, porque o bien no se construyó ningún inmueble de este tipo en los cien años que estudié, caso de la arquitectura hospitalaria, o bien sólo se hizo uno, caso de los cuarteles. Por ello, me circunscribí a los centros educativos y la vivienda, incluyendo en ésta las casas unifamiliares, las de vecindad y las obreras.

Por otro lado, justifiqué la no inclusión del análisis e interpretación de las distribuciones a la hora de abordar los edificios desde el punto de vista estilístico en el denominado "fachadismo", es decir, la concentración casi exclusiva del interés de los técnicos en el frente de las construcciones, circunstancia que fue muy característica de la arquitectura zamorana del período.

Respecto a las escuelas, las ordené en relación a los niveles educativos, primario, secundario y técnico, teniendo en cuenta tanto instituciones públicas como privadas. En el caso de las residencias particulares, el hecho de que las Ordenanzas Municipales exigieron acompañar las solicitudes de licencia de obras de un plano de planta desde 1890, fecha francamente temprana si lo comparamos con otras localidades cercanas, me permitió realizar un estudio más amplio y dar a conocer, por ejemplo, la evolución en las distribuciones, la pervivencia de algunas estancias, la aparición de las innovaciones técnicas y, en definitiva, el tipo de equipamiento.

Aún dentro del estudio de la arquitectura, hay un apartado dedicado a las intervenciones en el patrimonio, ámbito que por lo que respecta al caso concreto zamorano, salvo ejemplos aislados, nunca se había estudiado hasta el momento de forma global. En las páginas correspondientes quedó patente la incidencia de las diferentes corrientes restauradoras que han dominado el panorama español a lo largo de los últimos doscientos años. En este sentido, la actuación más sobresaliente fue la construcción de la cabecera de la iglesia del convento del Corpus Christi, de cuyo diseño final, de 1897, fueron responsables el sobrestante Eduardo Julián Pérez (titulado en 1862 y fallecido en 1898) y el arquitecto Vicente Lampérez (1861-1923, titulado en 1886). Algunas de las restauraciones que tuvieron lugar en la Catedral de Zamora en esta época, caso del cimborrio, eran muy conocidas, con artículos específi$\cos ^{22}$, pero aún así, aportó algunas noticias sobre obras menores llevadas a cabo en el Templo Mayor y sobre las actuaciones practicadas en otros monumentos de la ciudad, tanto civiles como religiosos.

Un capítulo de gran importancia es el de los protagonistas de la arquitectura y el urbanismo en Zamora. En él me pareció interesante incluir un primer apartado en el que expuse la evolución de los cargos de responsabilidad en las oficinas técnicas dependientes de las diferentes instituciones, con alusiones a los sucesivos concursos y sus correspondientes candidatos. Fue una tarea ardua y compleja pero consideré útil la reconstrucción de la secuencia de técnicos que ocuparon esos puestos por su propio interés, para 
el resto de mi trabajo y para ofrecer información valiosa a posibles investigaciones sobre los profesionales que cito. En un segundo bloque, expuse los datos biográficos y profesionales, en su mayoría inéditos, de todos los facultativos que trabajaron en la ciudad -arquitectos, maestros de obras, ingenieros, tanto militares como de caminos, canales y puertos, y sobrestantes de obras públicas-, hasta un total de cincuenta y dos. Incidí en aquéllos que residieron en el municipio de manera continuada, aunque, de cualquier manera, su número total demuestra la amplitud del trabajo. De entre todos ellos, y como ejemplo de las satisfacciones que dan investigaciones como ésta, hay que citar el gran descubrimiento de este estudio, el arquitecto Francesc Ferriol, cuyo interés excede con creces el ámbito estricto de Zamora. Como dije, gracias a mi tesis, se ha despertado en la ciudad un interés inusitado hacia su figura y, a instancias del Ayuntamiento, la localidad ha conseguido ingresar en la Ruta Europea del Modernismo, lo que ya ha tenido y tendrá amplias y variadas consecuencias.

Además, creí conveniente hacer referencia a otros protagonistas, caso de los escultores, los pintores, los artesanos, los contratistas y, naturalmente, la clientela, clasificando a los comitentes en diferentes categorías para dar a conocer su relevante participación en la historia de la arquitectura y el urbanismo en la ciudad.

Por último, como es habitual en este tipo de trabajos, incorporé sendos capítulos en los que recogí la bibliografía consultada y un extenso apéndice documental donde presenté diecinueve documentos de variada índole, representativos de la evolución arquitectónica y urbanística de la ciudad a lo largo de la centuria que estudié y, en definitiva, de la abundante documentación que consulté a lo largo de esos años.

Con todo ello, considero que cumplí con los objetivos marcados. En primer lugar, di a conocer la evolución urbanística de Zamora entre 1850 y 1950 y saqué a la luz una gran cantidad de documentación y planimetría absolutamente inédita, con lo que ofrecí un estudio riguroso de la transformación que sufrió el municipio en los siglos XIX y XX.

En segundo lugar, mostré la aportación de la capital objeto de mi estudio a la arquitectura española en las dos últimas centurias, en la que, como dije, destaca especialmente en el período que denominé Segunda Edad de Oro de la Arquitectura Zamorana, que, recuerdo, circunscribí al último cuarto del siglo XIX y las tres primeras décadas del siguiente. Esto no fue óbice para ampliar el marco cronológico y profundizar en el conocimiento de la arquitectura realizada antes y después de esas décadas de esplendor.

Por otro lado, saqué a la luz la labor realizada por notables profesionales de la arquitectura, tanto arquitectos como maestros de obras e ingenieros. Facultativos como Segundo Viloria, quien fue un excelente conocedor 
de los recursos facilitados por los nuevos materiales industriales, ladrillo y hierro. Gregorio Pérez Arribas, técnico perfectamente integrado en la sociedad local y, por ello, escogido por las clases más acomodadas para el diseño de sus viviendas. Francesc Ferriol, la gran aportación de este estudio; un arquitecto de gran calidad y maestría quien, como dije, introdujo el Modernismo catalán en Zamora y fue un revulsivo para sus colegas zamoranos, lo que permitió un enriquecimiento del lenguaje ecléctico que por entonces dominaba el panorama local. Antonio García Sánchez-Blanco, que supo evolucionar desde posiciones eclécticas cercanas al estilo Segundo Imperio hasta llegar el Art déco, pasando por el Regionalismo. Y, por último, Enrique Crespo Álvarez, máximo representante del Racionalismo y de la arquitectura zamorana en los años de la Posguerra. Todos ellos, junto con el maestro de obras Eugenio Durán, dejaron su impronta en la ciudad y participaron en la renovación de su caserío medieval.

Por último, di a conocer la contribución a la arquitectura zamorana de muchos arquitectos residentes en otras localidades, de manera que mi investigación ayuda a completar sus trayectorias, técnicos como Joaquín de Vargas, Antonio Iturralde, Santiago Madrigal, Miguel Mathet, Joaquín Secall o Jesús Carrasco-Muñoz, algunos de los cuales han sido referentes importantes a nivel nacional por distintas cuestiones, caso de Vicente Lampérez, Luis Moya, Joaquín Otamendi o Luis Menéndez-Pidal.

Concluyo afirmando que a pesar de las dificultades metodológicas planteadas en un trabajo de este tipo, todos los problemas que surgieron en el transcurso de su realización, los sinsabores que hubo a lo largo de esos años y las renuncias forzadas por la dedicación de tanto tiempo fueron compensados por las satisfacciones que jalonaron el proceso, por todo lo aprendido en lo relativo al proceso investigativo y, en especial, por el resultado final.

\section{NoTAS}

${ }^{1}$ El texto íntegro de la misma fue publicado por el Instituto de Estudios Zamoranos el año pasado [ÁVILA DE LA TORRE, Á.: Arquitectura y urbanismo en Zamora (1850-1950). Instituto de Estudios Zamoranos "Florián de Ocampo". Diputación de Zamora. CSIC. Zamora, 2009].

${ }^{2}$ MADOZ, P.: Diccionario geográfico-estadístico- bistórico de España y sus provincias de ultramar, tomo XV. Imprenta de Pascual Madoz. Madrid, 1849, pág. 495.

${ }^{3}$ Como bibliografía específica, vid., GÓMEZ MORENO, M.: Catálogo monumental de España. Provincia de Zamora. Ministerio de Instrucción Pública y Bellas Artes. Madrid, 1927; RAMOS DE CASTRO, G.: Arte románico en la provincia de Zamora. Diputación de Zamora. Zamora, 1977; RIVERA DE LAS HERAS, J. Á.: Por la Catedral, iglesias y ermitas de la ciudad de Zamora. 
Edilesa. León, 2001 y VV. AA.: Enciclopedia del Románico en Castilla y León. Zamora. Fundación Santa María la Real. Centro de Estudios del Románico. Aguilar de Campoo, 2002.

${ }^{4}$ RAMOS MONREAL, A. y NAVARRO TALEGÓN, J.: La fundación de los Morán Pereira. El hospital de la Encarnación. Diputación de Zamora. Zamora, 1990.

${ }^{5}$ CASQUERO FERNÁNDEZ, J. A.: "Transformaciones urbanas en la Zamora de la primera mitad del siglo XVIII. El gobierno del conde de Croix", Boletin de la Asociación Benito Pelletero (Zamora), año IX, nº 7, 1996, págs. 9-24 y RUPÉREZ ALMAJANO, Ma N.: "Aspectos del urbanismo zamorano en el siglo XVIII. La junta de policía", en VV. AA.: Primer Congreso de Historia de Zamora, tomo IV. Instituto de Estudios Zamoranos "Florián de Ocampo", Diputación de Zamora. Zamora, 1993, págs. 175-194.

${ }^{6}$ En referencia al urbanismo, hay una visión general realizada por José Luis Gago Vaquero (GAGO VAQUERO, J. L.: La arquitectura y los arquitectos del ensanche. Zamora 1920-1950. Instituto de Estudios Zamoranos “Florián de Ocampo", Diputación de Zamora. Zamora, 1988) y algunas breves pinceladas en investigaciones dedicadas a ámbitos concretos de la ciudad, caso de la Plaza Mayor [ÁVILA DE LA TORRE, Á.: "La destrucción parcial de la Plaza Mayor de Zamora", en VV. AA.: Actas del Congreso Internacional "La Plaza Eurobarroca". Ayuntamiento de Salamanca. Salamanca, 1999, págs. 171-176 y "La iglesia de San Juan de Puerta Nueva y su participación en la configuración de la Plaza Mayor zamorana", Salamanca, Revista de Estudios (Salamanca), nº 44, 2000, págs. 221-252 y FERRERO FERRERO, F.: La Plaza Mayor de Zamora. Ayuntamiento de Zamora. Zamora, 1988]. Respecto a la arquitectura ha habido aportaciones sobre edificios concretos, alusiones en libros que abarcaban ámbitos geográficos más amplios y algunas publicaciones de variada naturaleza y temática. Por citar algunos ejemplos: HERNÁNDEZ MARTÍN, J:: Guia de arquitectura de Zamora: desde los orígenes al siglo XXI. Colegio Oficial de Arquitectos de León. Delegación de Zamora. Zamora, 2004; CHÍAS NAVARRO, P. y ABAD BALBOA, T.: Los caminos y la construcción del territorio en Zamora. Catálogo de puentes. Instituto de Estudios Zamoranos "Florián de Ocampo", Diputación de Zamora. Zamora, 2004; HERRERO UÑA, M. A.: La arquitectura zamorana del siglo XX: el arquitecto Antonio García Sánchez-Blanco. Tesis doctoral. Universidad de Salamanca. Salamanca, 2007 (inédita) y VILORIA, A.: Segundo Viloria (1855-1923). Un arquitecto zamorano. Diputación de Zamora, Instituto de Estudios Zamoranos "Florián de Ocampo", Centro de Estudios Benaventanos "Ledo del Pozo", Delegación de Zamora del Colegio Oficial de Arquitectos de León y Funcoal. Zamora, 2007.

${ }^{7}$ Como somera bibliografía de la evolución urbanística de la Zamora medieval debemos citar: FERNÁNDEZ DURO, C.: Memorias históricas de Zamora, su provincia y obispado, tomos I y II. Establecimiento tipográfico de los sucesores de Rivadeneyra. Madrid, 1883; REPRESA, A.: "Génesis y evolución urbana de la Zamora Medieval", Hispania (Madrid) no XXXII, 1972, págs. 525-545; BUENO DOMÍNGUEZ, Ma L.: Historia de Zamora. Zamora en el siglo X. Fundación Ramos de Castro para el Estudio y Promoción del Hombre. Zamora, 1983 y VV. AA.: De los orígenes al final del Medioevo y La Edad Moderna, en ALBA LÓPEZ, J. C. (coord.): Historia de Zamora, tomos I y II. Instituto de Estudios Zamoranos "Florián de Ocampo", Diputación de Zamora y Caja España. Zamora, 1995. 
${ }^{8}$ En este sentido, la conservación del patrimonio es otro de los aspectos de la arquitectura de los siglos XIX y XX que resultan de mayor interés, no sólo en lo que se refiere a su vertiente práctica, sino en el conocimiento de sus planteamientos teóricos. En el caso de Zamora se han hecho algunas aportaciones al respecto, como TEIJEIRA PABLOS, Mª D.: "La demolición de la torre del Salvador de Zamora en el siglo XIX. Un debate sobre el concepto de patrimonio histórico", Anuario del Instituto de Estudios Zamoranos "Florián de Ocampo" (Zamora), 1999, págs. 135-139; "Las Comisiones de Desamortización y la conservación del patrimonio histórico en el siglo XIX: La Comisión Civil y la Comisión Científica y artística de Zamora (aspectos documentales)", en MORÁN SUÁREZ, Ma A. (Coord.): La documentación para la investigación: homenaje a José Antonio Martín Fuentes, volumen I. Universidad de León. León, 2002, págs. 539-552 y “La Comisión de Monumentos Históricos y Artísticos de Zamora en el siglo XIX", Anuario del Instituto de Estudios Zamoranos "Florián de Ocampo" (Zamora), 2002, págs. 323-336 y ÁVILA DE LA TORRE, Á.: "La conservación del patrimonio en Zamora a través de la labor de la Comisión Provincial de Monumentos", en VV. AA.: Actas del XIV Congreso Nacional del Comité Español de Historia del Arte, tomo III, volumen I. Universidad de Málaga. Málaga, 2006, págs. 291-304.

9 NAVASCUÉS PALACIO, P.: "El problema del eclecticismo en la arquitectura española del siglo XIX", Revista Española de Ideas Estéticas (Madrid), tomo XXIX, n 114, 1971, págs. 111-125.

${ }^{10}$ NAVASCUÉS PALACIO, P.: Arquitectura española (1808-1914). SUMMA ARTIS, volumen $\mathrm{XXXV}^{* *}$. Espasa Calpe. Madrid, 1996, pág. 535.

${ }^{11}$ HERNANDO CARRASCO, J.: Arquitectura en España 1770-1900. Manuales Arte Cátedra. Madrid, 1989, págs. 247 y ss.

${ }^{12}$ ADELL ARGILÉS, J. Ma: Arquitectura de ladrillos del siglo XIX. Técnica y forma. Fundación Universidad-Empresa. Madrid, 1987.

${ }^{13}$ RODRÍGUEZ ESTEBAN, Ma A.: El patrimonio de la arquitectura de ladrillo en Zamora. 1875 1930. Grado de Salamanca (inédito, defendido en septiembre de 2009).

${ }^{14}$ QUESADA MARTÍN, Mas J.: Daniel Zuloaga, 1852-1921. Caja de Ahorros de Segovia. Segovia, 1985 y RUBIO CELADA, A.: De la tradición a la modernidad: los Zuloaga ceramistas. TF. Editores. Madrid, 2007.

${ }^{15}$ Vid. GONZÁLEZ DELGADO, J. A. y HERMOSO NAVASCUÉS, J. L.: Jerónimo Arroyo López: Arquitecto. La Editora del Carrión. Palencia, 1999, págs. 145-147.

${ }^{16}$ Ver, BORRÁS GUALÍS, G.: "La arquitectura modernista en Teruel”, Teruel (Teruel), no 31, 1972, págs. 36-45 y PÉREZ SÁNCHEZ, A. y MARTÍNEZ VERÓN, J.: El modernismo en la ciudad de Teruel. Instituto de Estudios Turolenses. Teruel, 1998, págs. 72-80.

${ }^{17}$ En este sentido, vid., BUENO FIDEL, M. J.: Arquitectura y nacionalismo (pabellones españoles en las exposiciones universales del siglo XIX). Universidad de Málaga. Málaga, 1987.

${ }^{18}$ NAVASCUÉS PALACIO, P.: "Regionalismo y Arquitectura en España (1900-1930)", $A$. \& V. Monografías de arquitectura y vivienda (Madrid), n 3. Madrid, 1985, pág. 29. 
${ }^{19}$ Para estos dos arquitectos, vid., BASURTO FERRO, N.: Leonardo Rucabado y la arquitectura montañesa. Xarait Ediciones. Bilbao, 1986 y PÉREZ ESCOLANO, V.: Aníbal González: Arquitecto (1876-1929). Diputación Provincial de Sevilla. Sevilla, 1996 (reedición).

${ }^{20}$ En este sentido, vid., HOAG, J. D.: Rodrigo Gil de Hontañón: gótico y renacimiento en la arquitectura española del siglo XVI. Xarait Ediciones. Madrid, 1985 y CASASECA CASASECA, A.: Rodrigo Gil de Hontañón (Rascafría 1500 - Segovia 1577). Junta de Castilla y León. Valladolid, 1988.

${ }^{21}$ DÍEZ ELCUAZ, J. I.: Arquitectura y urbanismo en Salamanca 1890-1939. Colegio de Arquitectos de León. Delegación en Salamanca. Salamanca, 2003, págs. 289-297.

${ }^{22}$ MENÉNDEZ-PIDAL, L.: "Restauración del Cimborrio y de las cubiertas pétreas de la Catedral de Zamora", Archivo Español de Arte (Madrid), no XXXIV, 1961, págs. 193-213 y ARRECHEA MIGUEL, J. I.: "Luis Menéndez Pidal y la catedral de Zamora", en VV. AA.: Catedrales de Castilla y León, tomo 3. Junta de Castilla y León y Consejo Autonómico de los Colegios Oficiales de Arquitectos de Castilla y León. Valladolid, 1996, tomo 3, págs. 91-95. 